\title{
EL ABORTO EN LA JURISPRUDENCIA INTERNACIONAL, SUPRANACIONAL Y DE LA CORTE SUPREMA DE JUSTICIA ARGENTINA ${ }^{1}$
}

\author{
ABORTION IN INTERNATIONAL JURISPRUDENCE, \\ SUPRANATIONAL AND THE ARGENTINE SUPREME COURT OF JUSTICE
}

Por Facundo Pérez Lloveras (*)

Resumen: En el presente artículo se reseñan las principales resoluciones de las cortes, tribunales y comisiones internacionales, y de los tribunales supremos de diversos países que trataron el derecho a la vida de la persona por nacer y el derecho a la libre interrupción del embarazo por parte de la mujer.

Palabras claves: Aborto - Jurisprudencia

Abstract: This article outlines the main decisions of international courts, tribunals and commissions, and of the supreme courts of various countries that have dealt with the right to life of the unborn and the right to the free termination of pregnancy by the woman.

Keywords: Abortion - Jurisprudence

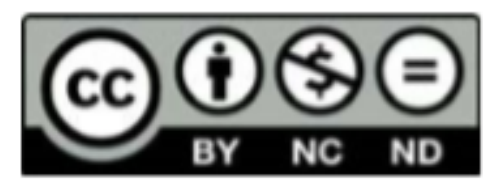

Artículo publicado bajo Licencia Creative Commons Atribución-No Comercial-Sin Derivar. (C) Universidad Católica de Córdoba

DOI http://dx.doi.org/10.22529/rfd.2020(3)04

\footnotetext{
${ }^{1}$ Artículo recibido el 23 de julio de 2020 y aprobado para su publicación el 10 de septiembre de 2020.

(*) Abogado (UNC). Especialista en Docencia Universitaria (UTN), Especialista en Derecho Penal Económico (UCLM - UNC); Profesor Titular de Derecho Penal Económico y Profesor Adjunto de Derecho Penal I (UCC). Correo electrónico: facundoperezlloveras@gmail.com
} 


\section{El derecho a la vida}

Tribunales de organismos internacionales, como así también de diversos piases a lo largo del mundo, intentan dilucidar la extensión del derecho al nacimiento con vida (o el de su contracara, el derecho a la libre interrupción del embarazo por parte de la mujer), y de ese modo buscan dar respuesta a cuestiones tales como si ese derecho es conferido por un ordenamiento legal, o si lo precede, si es absoluto o puede limitarse en determinados supuestos, si ceder frente al derecho de la mujer a disponer libremente sobre su cuerpo, etc.

En este trabajo se reseñan las principales resoluciones de los tribunales internacionales y de los máximos tribunales de diversos países que trataron el derecho a la vida de la persona por nacer y el derecho a la libre interrupción del embarazo por parte de la mujer.

\section{Jurisprudencia internacional}

Diversos tribunales de todo el mundo trataron la cuestión del derecho a la vida del nasciturus. Entre las resoluciones más icónicas se desatancan las siguientes:

\section{- Corte Suprema de los Estados Unidos de América}

La Corte Suprema de los Estados Unidos de América (CSEUA), en el caso "Roe vs. Wade" ${ }^{2}$ del año 1.973, estableció que el "nasciturus" no siendo una persona constitucional, solo se la protegía a partir de que fuese capaz de vivir con independencia de la madre. Según el fundamento de la sentencia, una ley o cualquier otra intervención del Estado que prohíba a la mujer disponer libremente

${ }^{2}$ Corte Suprema de los Estados Unidos de América, "Roe vs. Wade”, (1973, 410 U.S. 113).

\begin{tabular}{llll}
\hline REVISTA FACULTAD DE DERECHO & NUMERO 3 & 2020 & Página 123 \\
\hline
\end{tabular} 


\section{EL ABORTO EN LA JURISPRUDENCIA INTERNACIONAL, SUPRANACIONAL Y DE LA CORTE SUPREMA DE JUSTICIA ARGENTINA}

del "nasciturus" constituiría una violación ilícita de su derecho constitucional a la privacidad de la mujer. Esta decisión de la Corte fue interpretada como la despenalización del aborto para los estados de la Unión.

En el precedente de "Planned Parenthood vs. Casey"3, del año 1992, la CSEUA, declara la constitucionalidad de algunos procedimientos que someten la libertad de abortar a algunos controles y restricciones pero sin impedirla, señalando que los estados pueden regular el aborto, siempre y cuando dicha regulación no imponga “cargas excesivas” al derecho de las mujeres a solicitar su práctica.

En síntesis, en este caso la Corte reafirma el planteamiento esencial del fallo de Roe vs. Wade, lo que significó ratificar que la mujer tiene un derecho constitucionalmente protegido al aborto, pero a su vez destacó que el Estado tiene el poder de "restringir abortos", siempre y cuando la ley contenga excepciones para embarazos que pongan en peligro la vida o salud de la mujer.

\section{- Tribunal Constitucional de España}

El Tribunal Constitucional de España (TCE), en sentencia 53/19854, se refirió al tema del aborto y entendió que la protección que el Estado debe dispensar al no nacido implica dos obligaciones: la de "abstenerse de interrumpir o de obstaculizar el proceso natural de gestación" y la de establecer "un sistema legal para la defensa de la vida que suponga una protección efectiva de la misma y que, dado el carácter fundamental de la vida, incluya también, como última garantía, las normas penales". No obstante, tal protección no puede configurarse con un carácter absoluto pues "como sucede en relación con todos los bienes y derechos

3 Corte Suprema de los Estados Unidos de América. "Planned Parenthood vs. Casey", (1992, 112 S. Ct. 2791).

4 Tribunal Constitucional de España, "Recurso previo de inconstitucionalidad numero 80071983", (Sentencia 53/1985), publicada en BOE núm. 119, de 18 de mayo de 1985, disponible en https://boe.es/diario boe/txt.php?id=BOE-T-1985-9096, fecha de consulta 26 de julio de 2020. 


\section{EL ABORTO EN LA JURISPRUDENCIA INTERNACIONAL, SUPRANACIONAL Y DE LA CORTE SUPREMA DE JUSTICIA ARGENTINA}

constitucionalmente reconocidos, en determinados supuestos, puede y aún debe estar sujeta a limitaciones".

A continuación, el Tribunal reconoce la dignidad a todas las personas con carácter general, pero señala que el intérprete constitucional "no puede ignorar el hecho obvio de la especificidad de la condición femenina” y la concreción del libre desarrollo de la personalidad y los derechos a la integridad física y moral, a la libertad de ideas y creencias, al honor, a la intimidad personal y familiar y a la propia imagen en el ámbito de la maternidad, todos ellos "derechos que el Estado debe respetar y a cuya efectividad debe contribuir, dentro de los límites impuestos por la existencia de otros derechos y bienes asimismo reconocidos por la Constitución".

Además, admite la posibilidad de que en determinados casos el legislador ordinario pueda excluir de la protección penal la vida del no nacido. Se trata de situaciones de conflicto, en las que "la vida del nasciturus, como bien constitucionalmente protegido, entra en colisión con derechos relativos a valores constitucionales de muy relevante significación, como la vida y la dignidad de la mujer”. A partir de aquí, el Tribunal analiza los supuestos despenalizadores sometidos a examen y concluye que el legislador puede excluir al no nacido de la protección penal o, lo que es lo mismo, primar la voluntad de la mujer.

\section{-Tribunal Constitucional Federal de Alemania.}

El Tribunal Constitucional Federal de Alemania (TCFA) se ha pronunciado en dos ocasiones sobre el tema del aborto, en ambos fallos la discusión se centró en si la ley podía permitir el aborto consentido. 


\section{EL ABORTO EN LA JURISPRUDENCIA INTERNACIONAL, SUPRANACIONAL Y DE LA CORTE SUPREMA DE JUSTICIA ARGENTINA}

Así, el TCFA, en sentencia 39,1 del 25 de febrero de 1975, refiriéndose a la frase "todos tienen derecho a la vida", afirmó que el término "todos" se refiere a cada uno de los individuos humanos vivos, y por lo tanto, también al ser humano todavía no nacido. Su derecho a la vida prima sobre el derecho a la autodeterminación de la madre. El "nasciturus" no es un ser todavía no humano en vías de desarrollo hacia un estado humano, sino un ser humano que se está desarrollando como tal, y por lo tanto el nasciturus tiene derecho a la vida, no obstante, se debe considerar la constitucionalidad del aborto en determinadas circunstancias.

En una sentencia posterior, fechada el 28 de mayo de19935, el mencionado tribunal, afirma que la Constitución Alemana obliga al Estado a proteger la vida humana, incluyendo la vida del nasciturus. En esta línea de pensamiento, sostiene que el ordenamiento jurídico debe garantizar las concretas condiciones para el desarrollo de este derecho a la vida del no nacido, no dependiendo ésta de la exclusiva aceptación por parte de la madre. Así, se debe proteger jurídicamente al no nacido, incluso en contra del parecer de la mujer gestante.

A su vez TCFA contempla que el alcance del deber de protección de la vida del no nacido debe ser determinado atendiendo también a los bienes jurídicos que entran en conflicto. Así, junto al derecho la vida del no nacido, hay que tener en consideración los derechos de la mujer embarazada, en particular su derecho a la vida y la integridad física, como así también al respeto de su dignidad humana.

\section{- Corte Constitucional de Colombia}

5 Tribunal Constitucional Federal de Alemania, (2 BvF 2/90, 28 Mayo de 1993). Sentencia publicada en la revistas jurídicas: Neue JuTistische Wochenschrift 28 (1993) 1751-1779. Disponible en http://www.bverfg.de/e/fs19930528 2bvfooo2goen.html, fecha de consulta el 26 de julio del 2020. 


\section{EL ABORTO EN LA JURISPRUDENCIA INTERNACIONAL, SUPRANACIONAL Y DE LA CORTE SUPREMA DE JUSTICIA ARGENTINA}

La Corte Constitucional de Colombia en una sentencia del año $2006^{6}$ sostuvo que "el legislador, al adoptar normas de carácter penal, no puede desconocer que la mujer es un ser humano plenamente digno y por tanto debe tratarla como tal, en lugar de considerarla y convertirla en un simple instrumento de reproducción de la especie humana, o de imponerle en ciertos casos, contra su voluntad, servir de herramienta efectivamente útil para procrear”.

A su vez, la mencionada corte sostuvo que si bien corresponde al Congreso adoptar las medidas idóneas para cumplir con el deber de protección de la vida, esto no significa que estén justificadas todas normas que dicte con dicha finalidad, porque a pesar de su relevancia constitucional, la vida no tiene el carácter de un derecho absoluto y debe ser ponderada con los otros valores, principios y derechos constitucionales.

\section{Jurisprudencia de tribunales internacionales}

\section{-Comisión Interamericana de Derechos Humanos}

La Comisión Interamericana de Derechos Humanos (CIDH), en el Caso Baby Boy vs. EE.UU.7, fue el primer organismo interamericano en pronunciarse sobre el alcance de la protección que el sistema interamericano brinda a la persona por nacer. Lo hizo en el marco de una petición presentada en favor de un nonato que había sido abortado por una histerectomía practicada a su progenitora. Los peticionantes buscaban que la jurisprudencia de Roe v. Wade y Doe v. Bolton, que despenalizó el aborto voluntario en EE.UU., fuera declarada violatoria del derecho internacional.

${ }^{6}$ Corte Constitucional de Colombia, sentencia C-355 (2006).

7 CIDH, "Baby Boy vs. Estados Unidos de América”, caso No 2141, resolución No 23/81 (1981). 


\section{EL ABORTO EN LA JURISPRUDENCIA INTERNACIONAL, SUPRANACIONAL Y DE LA CORTE SUPREMA DE JUSTICIA ARGENTINA}

Respecto a este planteo, la CIDH resolvió que la decisión de la Corte Suprema de Estados Unidos y de la Corte Suprema Judicial de Massachusetts, no constituyen violación de los artículos "I" (derecho a la vida), "II" (derecho de igualdad ante la ley), "VII" (derecho de protección a la maternidad y la infancia) y "XI" (derecho a la preservación de la salud) de la Declaración Americana de los Derechos y Deberes del Hombre (DADDH).

En los fundamentos de su decisión, la CIDH señaló que la DADDH no fija una posición respecto al momento en que comienza la protección de la vida. Esta interpretación surge de la lectura del proyecto original de la DADDH, el cual establecía que "este derecho se extiende al derecho a la vida desde el momento de la concepción”, sin embargo, el texto finalmente aprobado limitó el alcance de la protección del derecho a la vida, en atención a las dificultades que el reconocimiento del momento de la concepción traía para diversas delegaciones, pues sus ordenamientos internos admitían el aborto.

\section{- Corte Interamericana de Derecho Humanos}

La Corte Interamericana de Derecho Humanos (Corte IDH) intervino en el debate sobre el alcance de la protección a la vida en el precedente Artavia Murillo y otros vs. Costa Rica ${ }^{8}$ (caso "fecundación in vitro").

En este caso, el Ministerio de Salud de Costa Rica dictó un decreto en el año1995, en el cual autorizaba la fecundación in vitro y regulaba su ejecución. El mismo año se presentó una acción de inconstitucionalidad contra el decreto en la que se alegaba sobre la violación del derecho a la vida. En el año 2000, la Sala Constitucional de la Corte Suprema de Costa Rica anuló el decreto mencionado. En

8 Corte IDH, “Artavia Murillo y Otros vs. Costa Rica”, (C No 257, del 20 de noviembre de 2012). 


\section{EL ABORTO EN LA JURISPRUDENCIA INTERNACIONAL, SUPRANACIONAL Y DE LA CORTE SUPREMA DE JUSTICIA ARGENTINA}

el año 2001 se presentó una petición a la CIDH y a petición de ésta, la Corte IDH tomó el caso y falló en el año 2012.

En su resolución la Corte recogió diversos antecedentes en los que se reconoce un legítimo interés en proteger la vida prenatal, pero donde se diferencia dicho interés de la titularidad del derecho a la vida, destacando que todo intento por proteger dicho interés debe ser armonizado con los derechos fundamentales de otras personas, especialmente de las gestantes.

En este precedente, la Corte IDH sostuvo que "el embrión no puede ser entendido como persona a los efectos del artículo 4.1 de la $\mathrm{CADH}$, pues una interpretación sistemática indicaría que, si bien muchos de los derechos de la CADH se dirigen a "toda persona”, no por ello se entiende que el embrión sea titular de los mismos. A su vez señaló que la expresión "ser humano", utilizada en el artículo 1 de la Declaración Universal de Derechos Humanos (DUDH) no fue entendida en el sentido de incluir al no nacido.

A su vez aclaró que la expresión "en general" utilizada en el articulo 4.1 de la $\mathrm{CADH}$ que califica la protección de la vida desde la concepción "se relaciona con la previsión de posibles excepciones a una regla particular" y por lo tanto se debe entender que la protección del derecho a la vida no es absoluta, "sino es gradual e incremental según su desarrollo, debido a que no constituye un deber absoluto e incondicional, sino que implica entender la procedencia de excepciones a la regla general”.

Por último se destaca que la Corte indicó que "el objeto y fin del artículo 4.1 de la $\mathrm{CADH}$ es que no se entienda el derecho a la vida como un derecho absoluto, cuya alegada protección pueda justificar la negación total de otros derechos”.

\section{-Tribunal Europeo de Derechos Humanos}




\section{EL ABORTO EN LA JURISPRUDENCIA INTERNACIONAL, SUPRANACIONAL Y DE LA CORTE SUPREMA DE JUSTICIA ARGENTINA}

Respecto de la protección de la vida de la persona por nacer, el Tribunal Europeo de Derechos Humanos (TEDH) ha señalado en reiteradas oportunidades ${ }^{9}$ que no es posible determinar cuándo comienza la vida humana en los términos del Convenio Europeo de Derechos Humanos (CEDH), ello pues, si bien este convenio establece en su artículo 2.1 que "el derecho de toda persona a la vida está protegido por ley", este instrumento no alude al momento en que se inicia la protección de la vida humana, ni califica la intensidad de la protección exigida y en tal sentido señala que el punto de partida temporal del derecho a la vida queda a criterio de la determinación de cada estado.

En este sentido el TEDH sostuvo en el caso "Costa y Pavan vs. Italia" (2013), que la potencialidad del embrión y su capacidad para convertirse en una persona no lo convierte en una "persona" con "derecho a la vida".

Por su parte, en el precedente "Evans v. The United Kingdom" (2007), el TEDH determinó que no vulneraba el derecho a la vida, la autorización realizada por el gobierno británico de destruir embriones contra el parecer de la futura madre, atendiendo al cambio de opinión del varón respecto de su paternidad, reafirmando así su postura de reconocer a cada Estado la potestad de decidir respecto a los derechos que confiere al embrión.

Respecto de un eventual derecho sustantivo al aborto, el TEDH, si bien no lo ha realizado de modo explicito, ha descartado la existencia del mismo al sostener que el derecho a la vida privada, artículo 8 del CEDH no confiere un derecho a abortar ${ }^{10}$. No obstante ello el Tribunal Europeo señaló que "la prohibición del

\footnotetext{
9 TEDH, "Vo c. Francia (2004), A, B, y C c. Irlanda" (2010), etc.

10 TEDH, "P. y S. v. Polonia” (2012) y “A, B, y C c. Irlanda” (2010).
} 


\section{EL ABORTO EN LA JURISPRUDENCIA INTERNACIONAL, SUPRANACIONAL Y DE LA CORTE SUPREMA DE JUSTICIA ARGENTINA}

aborto, cuando se pretende por razones de salud y/o del bienestar, caen en el ámbito de protección del derecho al respeto a la privacidad"11.

\section{III) Jurisprudencia de la Corte Suprema de Justicia de la Nación de Argentina}

El máximo precedente en la justicia argentina que trató la posibilidad de interrupción de un embarazo se dio con el caso "F., A.L. s/medida autosatisfactiva".

Si bien en este precedente la Corte Suprema de Justicia de la Nación (CSJN) no aborda el derecho a la libre disponibilidad de la mujer respecto a la vida del nasciturus que alberga en su vientre, si se pronuncia sobre los alcances del aborto legal previsto por la legislación argentina, en particular en el supuesto de interrupción de embarazos derivados de una relación sexual no consentida.

El caso se inició cuando la madre de A.G., invocando el artículo 86 del Código Penal, solicitó a la justicia de la provincia de Chubut que dispusiera la interrupción del embarazo que cursaba su hija de 15 años, por ser este producto de una violación. Luego de varias instancias que denegaban la posibilidad de abortar a la menor, el Superior Tribunal de Chubut admite la solicitud en beneficio de la adolescente, sosteniendo que el caso encuadraba en el supuesto de "aborto no punible” previsto en el inc. $2^{\circ}$, primera parte, del artículo 86 del Código Penal argentino y que esta hipótesis de interrupción del embarazo era compatible con el plexo constitucional y convencional.

La decisión del Superior Tribunal de Justicia de la provincia de Chubut fue recurrida mediante un recurso extraordinario por el Asesor General Subrogante de la provincia en representación del nasciturus. Su fundamentación la desarrolló bajo

${ }_{11}$ TEDH, "P. y S. v. Polonia (2012), Tysiac c. Polonia” (2007) y “A, B, y C c. Irlanda” (2010). 


\section{EL ABORTO EN LA JURISPRUDENCIA INTERNACIONAL, SUPRANACIONAL Y DE LA CORTE SUPREMA DE JUSTICIA ARGENTINA}

el hecho de la gravedad institucional que representaba el caso, debido a que con la interpretación llevada a cabo por el Superior Tribunal se había desconocido el plexo constitucional según el cual el Estado protege la vida desde la concepción, y no se encuentre el caso dentro de las excepciones autorizadas por la ley.

El asunto llegó a conocimiento de la CSJN, y aunque el aborto ya se había practicado, el tribunal entendió que era apto para su tratamiento, entre otros motivos, porque consideró necesario realizar una armonización de todo el plexo normativo en juego, con el propósito de poner fin a la controversia de si el Código Penal habilitaba únicamente el aborto cuando la víctima padecía una discapacidad determinada (interpretación restrictiva), o si la opción estaba disponible para cualquier mujer víctima de abuso (interpretación amplia).

En sentencia fechada el 13 de marzo de 2012, el Máximo Tribunal estableció que la Constitución Nacional y los tratados de derechos humanos no sólo impiden interpretar en sentido restrictivo el supuesto legal de aborto previsto por el art 86 inc. $2^{\circ}$ del C.P., sino que obligan a una interpretación donde se amplíen los supuestos legales de aborto mas allá de los previstos en la propia letra de la ley, entendiendo en consecuencia que no es punible el aborto practicado sobre un embarazo que sea consecuencia de una violación, con independencia de la capacidad mental de la víctima.

A los fines de dar sustento a su resolución, la Corte, a través de un análisis global, realiza una tarea de armonización que involucra la Constitución Nacional, los distintos tratados internacionales que forman parte esta ley suprema y las normas de derecho común aplicables al caso (artículo 86, inciso $2^{\circ}$ del Código Penal) con el objeto de dar respuesta a los cuestionamientos del apelante, rechazando cada uno de los agravios planteados.

En su resolución, la CSJN afirma que no es posible sostener que la interpretación del artículo 86, inciso $2^{\circ}$, del Código Penal adoptada por el Tribunal Superior de Chubut colisione con las normas constitucionales y supranacionales pues de estas 


\section{EL ABORTO EN LA JURISPRUDENCIA INTERNACIONAL, SUPRANACIONAL Y DE LA CORTE SUPREMA DE JUSTICIA ARGENTINA}

normas no surge ningún mandato de interpretar restrictivamente el art. 86 del código penal.

En este sentido, sostiene que tanto del artículo $1^{0}$ de la Declaración Americana de los Derechos y Deberes del Hombre, como del artículo $4^{0}$ de la Convención Americana sobre Derechos Humanos, no se deriva algún mandato por el que corresponda interpretar de modo restrictivo el alcance del artículo 86 inciso $2^{\circ}$, del Código Penal, ello pues las normas de estos instrumentos fueron expresamente delimitadas en su formulación para que de ellas no se derivara la invalidez de un supuesto de aborto como el de autos. En este particular, la Corte cita lo resuelto por la Comisión Interamericana de Derechos Humanos en el precedente "Baby Boy" del año 1981, que trata la discusión en torno a la redacción de los mencionados artículos.

A su vez, la Corte analiza la previsión contemplada en el artículo $3^{\mathrm{o}}$ de la Convención Americana sobre Derecho Humanos, en cuanto estipula el derecho de toda persona al reconocimiento de su personalidad jurídica, y entiende que tampoco se puede derivar de este instrumento, base alguna para sustentar la tesis de interpretación restringida del articulo 86 inc. $2^{\circ}$ del C.P., ello pues la propia Convención no quiso establecer una protección absoluta del derecho a la vida de la persona por nacer.

A su vez refiere que tampoco lo establecido en los artículos 3 y 6 de la Declaración Universal de Derechos Humanos, que consagran el derecho a la vida y el derecho al reconocimiento de la personalidad jurídica, son favorables para una interpretación restrictiva de la norma penal que se analiza, ya que dichos artículos deben ser interpretados en conjunto con lo previsto en el art. $1^{0}$ de la referida declaración, la que prevé que "todos los seres humanos nacen libres e iguales en dignidad y derechos y, dotados como están de razón y conciencia, deben comportarse fraternalmente los unos con los otros". 


\section{EL ABORTO EN LA JURISPRUDENCIA INTERNACIONAL, SUPRANACIONAL Y DE LA CORTE SUPREMA DE JUSTICIA ARGENTINA}

Entiende la Corte Suprema que tampoco puede ser sustentada la tesis restringida en el deber que emana del artículo $6^{0}$ del Pacto Internacional de Derechos Civiles y Políticos. En este particular destacó que el Comité de Derechos Humanos de Naciones Unidas ha manifestado su posición general relativa a que debe permitirse el aborto para el caso de embarazos que son la consecuencia de una violación. A su vez, señaló que al examinar la situación particular de nuestro país, el Comité ha expresado su preocupación por la interpretación restrictiva que la jurisprudencia realiza del artículo 86 del Código Penal. Por lo tanto, la Corte concluye que no es posible derivar de este tratado un mandato para interpretar restrictivamente la norma, sino que, inversamente, en atención a lo expuesto, se arriba a la conclusión contraria.

Con relación a las disposiciones de la Convención sobre los Derechos del Niño, la Corte entendió que tampoco es posible sostener que la interpretación del artículo 86, inciso $2^{\mathrm{O}}$ del Código Penal adoptada por el Tribunal Superior de Chubut colisione con las normas de dicha convención. Esto queda corroborado por la circunstancia que el Comité de los Derechos del Niño ha señalado que los Estados Partes que no admiten el aborto para el caso de embarazos que son la consecuencia de una violación, deben reformar sus normas legales incorporando tal supuesto y, respecto de nuestro país que sí lo prevé, ha manifestado su preocupación por la interpretación restrictiva que realiza la jurisprudencia del artículo 86 del Código Penal.

Por último, la Corte destaca que "los principios de igualdad y de prohibición de toda discriminación, que son ejes fundamentales del orden jurídico constitucional argentino e internacional y que en este caso poseen, además, una aplicación específica respecto de toda mujer víctima de violencia sexual, conducen a adoptar la interpretación amplia de esta norma", y señala los siguientes instrumentos para llegar a dicha conclusión: Constitución Nacional, artículo 16; Declaración Americana de los Derechos y Deberes del Hombre, artículo $2^{\mathrm{o}}$; Declaración 


\section{EL ABORTO EN LA JURISPRUDENCIA INTERNACIONAL, SUPRANACIONAL Y DE LA CORTE SUPREMA DE JUSTICIA ARGENTINA}

Universal de Derechos Humanos, artículos $2^{\circ}$ y $7^{\circ}$; Pacto Internacional de Derechos Civiles y Políticos, artículos 2.1 y 26; Pacto Internacional de Derechos Económicos, Sociales y Culturales, artículos $2^{\circ}$ y $3^{\circ}$, Convención Americana sobre Derechos Humanos, artículos 1.1 y 24; Convención sobre la eliminación de todas las formas de discriminación contra la mujer, artículos $2^{\mathrm{o}}, 3^{\mathrm{o}}$ y $5^{\mathrm{o}}$ a 16 , y Convención Interamericana para prevenir, sancionar y erradicar la violencia contra la mujer, artículos 4.f y 6.a.

Tras fijar el alcance de la norma cuestionada, la Corte fijó distintas pautas de implementación para asegurar el acceso efectivo a los abortos legales y la vigencia de los derechos humanos de las mujeres. En este sentido, se refirió a la ilegalidad de ciertas prácticas que demoran o impiden el acceso a los abortos legales, y que contrarían los estándares constitucionales e internacionales. Entre tales barreras ilegales, se refirió a la frecuente solicitud de una autorización judicial previa para la realización del aborto, a la exigencia de denuncia o elementos probatorios en casos de violación, a la intervención de más de un profesional de la salud, o la solicitud de consultas o dictámenes médicos o interdisciplinarios. Aclarando que, ante el pedido de la mujer embarazada, debe intervenir un único médico diplomado y no cabe requerir autorización o trámite judicial previo ya que la norma no lo prevé.

Por otra parte, la Corte Suprema consideró que el Estado, como garante del sistema de salud pública, debe asegurar las condiciones necesarias para que los abortos no punibles se lleven a cabo de manera rápida, segura y accesible, y exhortó a las autoridades nacionales y locales a implementar y hacer operativos protocolos hospitalarios de atención de los abortos no punibles. La Corte extendió así su preocupación respecto del fenómeno de inaccesibilidad a todos los supuestos de aborto legal contemplados, y no únicamente al referido a la situación particular de la demandante. 
EL ABORTO EN LA JURISPRUDENCIA INTERNACIONAL, SUPRANACIONAL Y DE LA CORTE SUPREMA DE JUSTICIA ARGENTINA 